\title{
PRÁticas de enSino de língua poRtugueSa COM AS tDics
}

\author{
Roberta Caiado ${ }^{1}$ \\ Artur Gomes de Morais ${ }^{2}$
}

\begin{abstract}
RESUMO:O objetivo desta pesquisa foi investigar o processo pedagógico que envolvia as práticas das professoras de Língua Portuguesa (doravante LP), especificamente, como elas utilizavam as novas Tecnologias Digitais da Informação e Comunicação (doravante TDICs) no ensino-aprendizagem de LP, nos anos finais do Ensino Fundamental. Realizamos um estudo qualitativo no qual observamos as aulas de três professoras de LP pertencentes a redes de ensino diferentes: federal, estadual e privada. Estabelecemos categorias de análise, que emergiram da observação da práxis das professoras. Em seu marco teórico, a presente pesquisa se inscreve nos estudos sobre transposição didática, transposição informática, multiletramentos e letramento digital, assumindo como perspectiva teórica a linguagem em sua natureza social e dialógica, produzida como ação humana. Constatamos que as três professoras possuíam práticas diferenciadas no que concerne ao uso das TDICs. Os resultados sinalizaram para a falta ou carência na formação de algumas professoras para a utilização da tecnologia digital como meio de aprendizagem e revelaram a sua utilização como fator motivacional na maior parte das aulas de LP. Acreditamos que há necessidade de a instituição escolar modificar seus currículos de LP e assumir, em seu projeto político-pedagógico, as TDICs na qualidade de elementos estruturantes de novos processos educativos.
\end{abstract}

Palavras-chave: Ensino-aprendizagem. Língua portuguesa. Prática pedagógica. Tecnologia digital.

\section{PRACTICE TEACHING OF PORTUGUESE LANGUAGE WITH TDIC}

\begin{abstract}
The objective of this research was to investigate the educational process involving the practices of teachers of Portuguese Language (henceforth LP), specifically, how they used the new digital technologies of information and communication (henceforth TDIC) in teaching-learning of LP, in the final years of elementary school. We conducted a qualitative study in which we observed three classes of LP teachers belonging to different school systems: federal, state and private. Established categories of analysis, which emerged from the observation of the practice of teachers. In his theoretical framework, this research is included in the studies of didactic transposition, transposition computer, multiliteracies and digital literacy, assuming as a theoretical perspective the language in its social and dialogical nature, produced as human action. We note that the three teachers had different practices regarding the use of TDIC. The results signaled the absence or lack the training of some teachers to use digital technology as a means of learning and showed its use as a motivational factor in most classes of LP. We believe there is a need for educational institutions to modify their curriculums of LP and take in his political pedagogical project, TDIC as the structural elements of new educational processes.
\end{abstract}

KEYWORDS: Teaching-learning. Portuguese. Teaching practice. Digital technology.

\footnotetext{
${ }^{1}$ Linguista. Doutora em Educação pela Universidade Federal de Pernambuco. Professora Pesquisadora do Programa de Pós-graduação - Mestrado em Ciências da Linguagem da Universidade Católica de Pernambuco. Recife - PE - Brasil; E-mail: r.caiado@globo.com

2 Psicólogo. Doutor em Psicologia pela Universidade de Barcelona. Professor Titular do Centro de Educação da Universidade Federal de Pernambuco. Recife - PE - Brasil; E-mail: agmorais@uol.com.br Recebido em: 29/10/2013 - Aceito em: 14/11/2013.
} 


\section{PRÁCTICAS DE ENSEÑANZA DE LENGUA PORTUGUESA CON LAS TDIC}

RESUMEN: Esta investigación tuvo por objetivo investigar el proceso pedagógico involucrado em las prácticas de profesoras de Lengua Portuguesa (LP), más especificamente cómo ellas empleaban las nuevas tecnologías digitales de información y comunicación (TDIC) en la enseñanza de LP, en los últimos años de la educación fundamental. Desarrollamos um estudio cualitativo en el que observamos clases de tres profesoras que actuaban em distintas redes de enseñanza: federal, estadual y privada. Establecemos categorias de análisis, que han emergido de la observación de las práxis de las docentes. En su marco teórico, esta investigación se inscribe en los estudios sobre transposición didáctica , transposición informática, multiletramentos y letramento digital, adoptando como perspectiva teórica el lenguaje en su naturaleza social y dialógica, producido en tanto acción humana. Concluímos que las tres profesoras tenían prácticas diferenciadas en lo que respeta al empleo de las TDIC. Los resultados han indicado la falta de formación de algunas docentes para el uso de la tecnologia digital en tanto médio de aprendizaje y han revelado su empleo como factor motivacional en la mayor parte de las clases de LP. Creemos que hace falta que la institución escolar cambie los currículos de LP y que trate las TDIC, en su proyecto político pedagógico, como elementos estructurantes de nuevos procesos educativos.

PALABRAS ClAVE: Enseñanza-aprendizaje. Lengua portuguesa. Práctica pedagógica. Tecnología digital.

\section{INTRODUÇÃ̃o}

O objetivo desta pesquisa foi investigar o processo pedagógico que envolvia as práticas de três professoras de Língua Portuguesa (doravante LP), pertencentes a redes de ensino diferentes: federal, estadual e privada, especificamente, como elas utilizavam as novas Tecnologias Digitais da Informação e Comunicação (doravante TDICs) no ensino-aprendizagem de LP nos anos finais do Ensino Fundamental. Daremos início às reflexões que fundamentam nossas análises sobre a prática pedagógica das professoras de LP tendo por base a Teoria da Transposição Didática (doravante TD), primeiramente, e, posteriormente, a Teoria da Transposição Informática (doravante TI), numa tentativa de ampliação e enriquecimento do processo de TD relacionado, especificamente, ao uso das tecnologias digitais - computador interligado à Web 2.0 - no ensino.

O conceito de TD foi proposto, inicialmente, pelo sociólogo francês Michel Verret, que criou o termo para nomear as transformações pelas quais passa o saber ensinado na escola. Em 1985, Yves Chevallard, pesquisador da didática de Matemática, publica La Transposition Didactique: du savoir savant au savoir enseigné. Esse autor amplia e organiza o conceito de TD, que, em sentido restrito, designa a passagem do saber sábio ao saber ensinado. Chevallard (1991, p. 45) define Transposição Didática como:

Un contenido de saber que ha sido designado como saber a enseñar, sufre, a partir de entonces, un conjunto de transformaciones adaptativas que van a hacerlo apto para ocupar un lugar entre los objetos de enseñanza. El trabajo que transforma de un objeto de saber a enseñar en un objeto de enseñanza, es denominado la transposición didáctica. 
Chevallard (1991) parte do pressuposto de que o ensino do saber sábio, também denominado científico ou acadêmico, só será possível se esse saber sofrer certas "deformações" para que esteja apto a ser ensinado, pois, no seu entendimento, existe uma grande distância que separa os saberes sábios dos saberes escolares.

Voltando nosso olhar para a disciplina de LP, relembramos que, nas últimas décadas, passamos a defender que o objetivo primeiro da aprendizagem de língua materna é o desenvolvimento das competências linguísticas, respeitando-se as diversidades cognitivas, sociolinguísticas, socioculturais dos educandos. Dessa forma, a oralidade, a escrita, a leitura, a gramática da língua passaram a ser vistas como competências a serem desenvolvidas na escola, e fora dela, e exercidas em práticas sociais de interação entre interlocutores.

A partir do exposto, acreditamos que os conteúdos a ensinar na escola, na disciplina de LP, não se limitam aos saberes científicos transpostos, tão somente, mas, também, e ao mesmo tempo, ao que Martinand (1986) denomina de as "práticas sociais de referência". Devido a isso, as tecnologias digitais integram a cadeia dos multiletramentos na escola e precisam ser compreendidas como um dos fatores propiciadores do "plurilinguismo, da diversidade cultural, das multissemioses", o que implica uma nova ética e novas estéticas, enfim numa pedagogia dos multiletramentos (KALANTZIS; COPE, 2000).

Assim, para o desenvolvimento dessa pesquisa sobre novas TDICs, buscamos fundamentação, também, na teoria da Transposição Informática, que foi inicialmente enunciada pelo estudioso francês em Educação Matemática Nicolas Balacheff. A TI estuda a transposição dos saberes sábios para o meio digital, de acordo com as exigências específicas dos meios eletrônicos. Em outras palavras, é o processo em que o conhecimento, tendo origem em um saber sábio de referência e sendo dirigido para determinado saber aprendido pelo estudante, passa, necessariamente, por uma modelização informatizada (BALACHEFF, 1991). No nosso entendimento, a TI parte de um pressuposto fundamental da TD - a transposição de um conhecimento de uma determinada área do saber para outra - porém possui especificidades relacionadas aos meios digitais. Balacheff (1994) entende que os ambientes digitais de aprendizagem são espaços de aprendizagem e oferecem novos objetos de ensino (a leitura de hipertextos hipermodais ou a produção de gêneros digitais poderiam ser exemplos de atividades em ambientes digitais de aprendizagem relacionados à LP).

As escolas precisam, diante dos desafios impostos pelos multiletramentos, abrir espaço para a diversidade, para a multiplicidade de interpretação dos signos, para as intenções dos alunos - produtores e coprodutores dos significados. Segundo Bonilla (2009, p. 35): 
A contemporaneidade está a exigir que a escola proponha dinâmicas pedagógicas que não se limitem à transmissão ou disponibilização de informações, inserindo nessas dinâmicas as TICs, de forma a reestruturar a organização curricular fechada e as perspectivas conteudistas que vêm caracterizando-a. A escola necessita ser um ambiente no qual a vasta gama de informações a que os alunos têm acesso seja discutida, analisada e gere outros conhecimentos, no qual as tecnologias sejam inseridas como elementos estruturantes de novas práticas, práticas que comportem uma organização curricular aberta, flexível.

As TDICs podem favorecer os multiletramentos colocando-se como desafios às práticas escolares em favor das práticas sociais a que os alunos têm acesso (LEMKE, 1998; ROJO, 2012).

\section{A METODOLOGIA DA PESQUISA}

Para observar as práticas de ensino com as TDICs, realizamos um estudo qualitativo no qual presenciamos as aulas de professoras de LP. A modalidade da observação e registro em um diário de campo - enquanto método de coleta de dados ajudou-nos a entender o "como" e o "porquê" das práticas pedagógicas relacionadas ao uso das TDICs em sala de aula. Elencamos categorias de análise (BARDIN, 1979) que emergiram da observação da práxis das professoras num diálogo constante entre a teoria apresentada na pesquisa e os dados observados.

Nosso corpus, no presente estudo, foi assim constituído: acompanhamos a prática de três professoras pertencentes a redes de ensino e escolas diferentes. O critério de seleção levou em consideração as professoras que utilizassem, sempre, as TDICs nas suas aulas de LP. Dessa forma, observamos as aulas da: Professora 1, que pertencia à rede federal de ensino (doravante $\mathrm{P} 1$ - $\mathrm{CF}$ ); Professora 2, que pertencia à rede privada de ensino (doravante P2 - CP); Professora 3, que pertencia à rede estadual de ensino (doravante P3 - CE).

Ao longo da pesquisa, P1 (CF) realizou três projetos relacionados ao uso das TDICs no ensino-aprendizagem de LP. Um primeiro, cujo objetivo era que o aluno conhecesse ou se familiarizasse com o gênero digital $e$-mail, o segundo relacionava-se ao uso do gênero digital weblog e o terceiro era a criação de uma história em quadrinhos (doravante HQ) digital.

P2 desenvolveu três projetos ao longo das aulas observadas. O primeiro dizia respeito ao bullying na rede digital, discussões sobre a rede e seus usos: benefícios e malefícios. O segundo consistia na criação de uma HQ digital a partir da leitura do livro paradidático Presas na Teia, da autoria de Rosana Hermann. O terceiro relacionava-se, 
também, ao livro citado acima; os alunos deveriam escrever um texto de opinião sobre o livro - consistia na edição de texto no documento Word.

P3 desenvolveu dois grandes projetos de retextualização de textos. O primeiro relacionava-se, tematicamente, à Copa do Mundo de Futebol e o segundo, ao tema Gravidez na Adolescência. Ela também colocou-nos a par de suas dificuldades com relação ao laboratório de informática da escola. Relatou que não havia interesse por parte da direção da escola nesses projetos relacionados às novas TDICs, mesmo tendo em conta que a proposta curricular do CE diferenciava-se por utilizar recursos tecnológicos relacionados à informática, com carga horária específica, em algumas disciplinas. P3 só utilizava em seus projetos softwares livres, baixados pelo webmaster, com o qual trabalhava em conjunto.

Observamos que alguns fatores influenciavam diretamente o trabalho docente com as TDICs e deles dependiam as práticas exercidas pelas professoras de LP. Assim, optamos por elencar categorias de análise das práticas pedagógicas exercidas pelas professoras de LP, levando-os em consideração: Uso do tempo no trabalho didático com as TDICs na escola; Espaço: onde ocorria a aula quando se empregavam, na escola, as novas TDICs; Programador, webmaster, chefe da informática ou coordenador do laboratório de informática; Mediação: presença do professor (ou não) no laboratório de informática da escola; Formas de organização do trabalho docente: planejamento das aulas no laboratório de informática da escola; Recursos tecnológicos utilizados no laboratório de informática; Dinâmica da aula de LP no laboratório de informática da escola; Usos e efeitos das TDICs: atividades de LP solicitadas aos alunos no laboratório de informática da escola.

\section{USO DO TEMPO NO TRABALHO DIDÁtiCO COM AS tDICS NA ESCOLA}

Acreditamos que a inserção do computador, como meio de aprendizagem, na educação, instiga uma reflexão sobre a noção de tempo. Na TD são colocadas duas variáveis fundamentais para compreensão da natureza da educação escolar: o tempo didático e o tempo de aprendizagem. Segundo Chevallard (1991, p. 75): "Esa relación saber/duración es el elemento fundamental del proceso didáctico 3 ".

O tempo didático cumpre uma exigência do planejamento pedagógico (aula, unidade de ensino...). Caracteriza-se por ser linear, cumulativo e sequencial para efeito do ensino disciplinar e pressupõe que seja possível delimitar o tempo de aprendizagem. Este se caracteriza pelos conflitos múltiplos e individuais de cada aluno frente ao processo de elaboração do conhecimento. O tempo de aprendizagem não é linear, não é

2. Tradução nossa: "Essa relação saber/duração é o elemento fundamental do processo didático". 
sequencial, pois busca conhecimentos prévios para transformá-los, ampliá-los, reorganizá-los, diante das novas situações de aprendizagem vivenciadas.

Observamos três realidades distintas relacionadas ao tempo didático no laboratório: P3 planejava e realizava suas aulas no dia em que possuía quatro horas/aula de LP com os alunos; P1 realizava suas aulas no tempo que lhe fosse disponibilizado pelo responsável pelo laboratório, o que acontecia em uma ou duas horas/aula, qualquer dia da semana; P2 planejava e realizava suas aulas no dia que tinha aula conjugada de LP - duas horas/aula - e que a professora da disciplina de Artes estivesse com a outra metade da turma.

A partir das observações realizadas, emergiu o seguinte questionamento com relação ao tempo: como poderia o tempo didático influenciar o "resultado esperado" para o ensino-aprendizagem de LP no laboratório de informática? Para responder a esse questionamento, inferimos que os alunos observados dos três colégios - nativos digitais que são - já haviam se apropriado, anteriormente, do saber relacionado à mídia digital no processo de elaboração do conhecimento propiciado pelo tempo de aprendizagem, pois eram capazes de conciliar as orientações pedagógicas, daquele breve momento, com a criatividade, autonomia e iniciativa necessárias a quem já se apropriou de um saber.

\section{ESPAÇ: ONDE OCORRIA A AULA QUANDO SE EMPREGAVA NA ESCOLA AS NOVAS TDICS}

Observamos os locais nos quais ocorreram as aulas de LP das professoras que utilizaram as novas TDICs na sua prática. Com exceção de uma aula da P2, na qual a mesma propôs um amplo debate sobre uma reportagem de jornal que enfocava o bullying na internet, ministrada em sala de aula, todas as demais aulas observadas de P1, P2 e P3 aconteceram no Laboratório de Informática das escolas em que trabalhavam.

É importante salientar que esse era um dos pré-requisitos dessa pesquisa: todas as escolas onde realizamos nossa investigação deveriam possuir um laboratório de informática interligado à Web 2.0. Uma das razões que poderíamos aqui elencar é a de que o simples deslocamento de um espaço já conhecido - sala de aula - no qual o modelo-padrão linear de ensino ainda funciona em algumas instituições, para um espaço novo, que é o espaço do laboratório de informática, recheado de tecnologia digital, que o aluno - nativo digital - já utiliza em suas práticas cotidianas fora da escola, é um fator motivacional importante a ser considerado, como pudemos observar.

As atividades de LP tornam-se especialmente atraentes, instigantes, significativas para o aluno, quando é possível visualizar, ouvir e sentir o que está sendo estudado, devido à multimodalidade propiciada pelas novas TDICs. A inserção das 
novas TDICs no espaço institucional escolar permitiria desenhar uma nova configuração desse espaço e implementar novas formas de se relacionar com ele. P1, P2, P3, a partir desse novo espaço de aprendizagem, teriam que, necessariamente, planejar novas práticas educativas, desenvolver novos tipos de interação com seus alunos, pois o espaço do laboratório de informática requer uma dinâmica de aula diferente.

Algumas aulas observadas nos fizeram inferir que o espaço escolar - laboratório de informática - ainda pode ser visto e sentido como um "apêndice", que reforçaria a manutenção de outro ensino, que não envolveria as novas TDICs, e só ocorreria na sala de aula. Isso porque, algumas vezes, houve a preocupação de estar no espaço do laboratório de informática para se utilizar a máquina pela máquina, ou seja, substituiu-se o papel, o lápis e a borracha, pela tela e o teclado do computador.

Uma realidade registrada em todas as aulas de P1 e P2 era a falta de finalização da atividade solicitada de LP, prevista para ser realizada no laboratório de informática, tendo em vista o tempo de uso do espaço. Não houve registro de retorno ao laboratório de informática em dias posteriores, objetivando finalizar a atividade da aula anterior. A atividade proposta era finalizada, sempre, em casa, e deveria ser enviada para o e-mail da professora.

No que diz respeito às aulas de $\mathrm{P} 3$, a atividade de LP do dia era proposta e realizada dentro do tempo previsto, ou seja, os alunos iniciavam e terminavam a atividade no laboratório de informática e o webmaster, que acompanhava o trabalho da professora, gravava, em um único pen drive, o produto final das atividades realizadas pelas duplas de alunos.

Podemos inferir que as atividades solicitadas pelas professoras poderiam estar "mal dosadas" para o tempo que os alunos passariam no laboratório de informática e/ou que algumas atividades propostas exigiam mais tempo para ser realizadas, como por exemplo, uma atividade proposta por P1, que envolvia, além da criação do texto, a pesquisa na ferramenta de busca do Google sobre os personagens que os alunos desejassem inserir em uma HQ.

\section{PROGRAMADOR, WEBMASTER, CHEFE DA INFORMÁtICA OU COORDENADOR DO LABORATÓRIO DE INFORMÁTICA?}

A figura do Programador integra a cadeia da TI (CONRAUX, 2000). Constatamos que, realmente, a TI se evidenciava quando o programador "colaborava" com o professor, definindo um conhecimento de referência, os modelos disponíveis de acordo com as necessidades da atividade, um software específico e a linguagem de programação a ser utilizada. Passamos a descrever abaixo "quem" encontramos nas três 
escolas que poderia realizar o trabalho proposto pela TI em parceria com as professoras observadas.

a) No CF existia o professor de informática, que trabalhava com projetos específicos na área de informática. Ele ministrava a disciplina de Matemática e não acompanhava os professores das demais disciplinas quando iam ao laboratório. A sua função era ministrar aulas de informática, agendar o laboratório para uso dos demais professores, disponibilizar softwares para as atividades propostas pelos professores.

b) No $\mathrm{CP}$ existia um núcleo de informática, no qual trabalhavam duas pessoas que realizavam a função do programador da TI, denominadas de: chefe de informática e auxiliar de informática. Em todas as aulas observadas por nós, registramos a presença do auxiliar de informática no recinto do laboratório de informática. Pelos depoimentos coletados de P2 e pelas observações realizadas, podemos concluir que, realmente, havia um planejamento conjunto entre ela, a chefe e o auxiliar do laboratório do colégio. O auxiliar do laboratório salvava atividades realizadas pelos alunos, disponibilizava essas atividades para os próprios alunos e professora, bem como os softwares a serem utilizados nas aulas, e dava suporte técnico, quando a ferramenta não ajudava. O planejamento realizado em conjunto não só contribuía para o ensino-aprendizagem dos alunos, como para a formação da professora de LP, que se confessava leiga na área das tecnologias digitais, sem, contudo, interferir no conteúdo da disciplina de LP, que era de seu inteiro domínio.

É assim que entendemos a concretização da TI, no que diz respeito à entreajuda do experimentador (professor) e do programador (especialista na área). Consideramos relevante que o espaço de utilização das TDICs conte com um responsável técnico em tempo integral, que planeje junto, acompanhe e interfira no andamento da aula ministrada, no que tange à ferramenta disponibilizada para o aluno e selecionada pelo professor para o saber ser efetivamente ensinado, concretizando a TD.

c) No CE não existia nenhum responsável pelo laboratório. P3 conhecia um aluno da escola na qual ministrava aulas, que cursava o $3^{\circ}$ ano do Ensino Médio à época, tinha 17 anos, e morava na mesma comunidade da professora, na qual ministrava aulas de informática em uma ONG - ele era autodidata. Até as normatizações dos softwares e as próprias instruções de uso, que, geralmente, são escritas em inglês, o aluno colocava na ferramenta de tradução do Google para ter acesso ao máximo que aquele programa poderia oferecer. P3 resolveu "adotá-lo" como "seu" webmaster - como o denominava, nas turmas nas quais ministrava aulas no período vespertino. Segundo nos relataram P3 e o webmaster, o planejamento era todo realizado em conjunto na ONG da 
comunidade, onde também ele era testado. O webmaster, a partir das ideias de P3, baixava programas gratuitos da internet e os testava na frente da professora para verificarem, juntos, se o programa era compatível com a atividade de LP que a professora desejava implementar ou se o software era de fácil acesso e compreensão para os alunos do CE. A professora detinha o conhecimento específico e necessário à realização da atividade de LP e o webmaster entrava com o conhecimento técnico (de uso da ferramenta, da máquina) com o qual esses alunos tinham mais dificuldade que os demais observados, pertencentes aos colégios CF e CP. P3 afirmou que sem a "ajuda/parceria" do webmaster seu projeto de "Retextualização: da escrita textual para escrita hipertextual" não aconteceria.

\section{MEDIAÇÃO: PRESENÇA dO PROFESSOR (OU NÃO) NO LABORATÓRIO DE INFORMÁTICA DA ESCOLA}

Diversas variantes compunham o quadro da presença ou ausência da professora nesse espaço midiático. E a ausência aconteceu por motivos que independiam da vontade das docentes, mas, antes sim, demonstraria o quanto o trabalho didático com as novas TDICs é relegado a segundo plano ou demonstraria o despreparo das instituições para acolher essa prática pedagógica, ainda que ela seja uma prática social cotidiana dos nativos digitais.

Observamos que P1 tinha duas práticas pedagógicas quando utilizava o laboratório de informática da escola: levava a turma toda para o laboratório e lá permanecia a aula toda com os alunos, que trabalhavam em duplas neste dia; levava metade da turma em um dia, dava as orientações necessárias para que eles iniciassem o trabalho, individualmente, saía para ministrar outro conteúdo para o restante da turma que permaneceu em sala de aula, e, em outra oportunidade, realizava a mesma atividade com o restante da turma. Analisando as duas situações, constatamos que a presença da professora durante a aula toda, orientando, motivando, instigando, partilhando opiniões e interagindo com os alunos representava um diferencial no ensino com as novas TDICs. Essa intervenção poderia provocar uma reflexão mais aprofundada, uma revisão ou confrontamento de conceitos e, posteriormente, propiciar o início de um processo de aprendizagem em LP.

A prática de $\mathrm{P} 2$ diferenciava-se da prática de P1, pois havia tanta preocupação em acompanhar as atividades realizadas pelos alunos no laboratório de informática, que o dia da aula no recinto era sempre agendado e minuciosamente planejado (troca de horários com professores de outras disciplinas), o que lhe propiciava estar neste espaço com os alunos. 
No que diz respeito à prática da $\mathrm{P} 3$, observamos que ela estava sempre presente quando realizava um projeto no qual utilizaria as novas TDICs no laboratório de informática, o que envolvia um planejamento prévio intenso, devido à necessidade da presença do aluno-webmaster. Os alunos do CE nos pareceram "mais dependentes" da presença da professora e do webmaster, comparativamente aos alunos do CF e CP. Isso pode ter acontecido pelo grau de dificuldade da atividade de LP solicitada aos alunos ou pela menor intimidade com as TDICs demonstrada por esses alunos, se comparados aos demais observados. Em um depoimento, a professora afirmou que sem a presença do webmaster não teria conseguido realizar o projeto. Acrescentaríamos que sem a presença de P3 junto ao webmaster o projeto não seria tão significativo para o ensinoaprendizagem dos alunos do $\mathrm{CE}$, porque o webmaster detinha os conhecimentos técnicos da ferramenta e a professora detinha os conhecimentos da disciplina LP, ou seja, dos conteúdos a serem transpostos para a sala de aula.

Dessa forma, acreditamos que a presença dos professores de LP e do programador, no espaço específico para utilização das TDIC, favorece o ensinoaprendizagem de LP, na medida em que os professores têm a oportunidade de envolverse, em diferentes graus, durante o processo de reorganização das funções cognitivas do aluno.

\section{FORMAS DE ORGANIZAÇÃo do trabalHO DOCENTE: PLANEJAMENTO DAS AULAS NO LABORATÓRIO DE INFORMÁtICA DA ESCOLA}

Registramos que as três professoras observadas planejavam a aula de LP ministrada no laboratório de informática, seja no que diz respeito à atividade a ser proposta para os alunos, seja no agendamento do laboratório, seja no planejamento conjunto com o programador.

Dessa forma, no CP, quando os alunos entravam no laboratório, as máquinas já estavam ligadas e o monitor de cada computador continha o programa selecionado por P2 para a atividade de LP.

No CF a própria professora $\mathrm{P} 1$ abria a sala; os alunos ligavam os computadores sozinhos e ela dava as orientações de busca do programa que iriam utilizar naquela aula, previamente instalado pelo programador. Quando P1 agendava o laboratório, já dizia ao programador qual software utilizaria e ele o disponibilizava nas máquinas.

No CE, P3 e o aluno-webmaster entravam juntos no laboratório, ele ligava todos os computadores e dava orientações aos alunos de como acessar o software gratuito que iriam utilizar. Após essa primeira orientação técnica, P3 iniciava suas orientações sobre a atividade de LP. Observamos que quando desejava suporte técnico "mais avançado", ela solicitava a intervenção do webmaster; outras vezes ela mesma dava orientações 
acerca da ferramenta em uso. Nos três casos em estudo houve planejamento conjunto entre professoras e programadores, porém em graus distintos.

\section{RECURSOS TECNOLÓGICOS UTILIZADOS NO LABORATÓRIO DE INFORMÁTICA}

Ao longo das observações realizadas, tivemos a oportunidade de conhecer e entrar em contato com os aplicativos utilizados pelas professoras para realização das atividades e projetos de LP propostos. As professoras P1 e P3 utilizaram softwares livres para realizar e concretizar as atividades planejadas, enquanto P2 utilizou-se das ferramentas programas e sugestões de atividades disponibilizadas por um Portal. As inúmeras possibilidades de uso dos softwares livres tornava a produção dos alunos mais criativa, pois as alternativas eram infinitas. Os programas eram de fácil acesso e, geralmente, o produto produzido podia ser disponibilizado em rede para interlocutores reais.

A P2 utilizava-se de um Portal, que é um ambiente de conhecimento, ensino e aprendizagem, ao qual escolas privadas podiam associar-se, tornando-se parceiras no projeto. Ao associar-se, a escola, que pagava por esse serviço, passava a ter sua própria homepage, na qual podia disponibilizar aos alunos e professores conteúdos e serviços próprios. O Portal pareceu-nos diretivo, no sentido de que retirava as possibilidades de criação do professor, pois as atividades solicitadas aos alunos deviam estar contempladas nele para serem realizadas. Pareceu-nos, também, homogenizador, pois devido às próprias limitações do ambiente de ensino-aprendizagem, as produções dos alunos eram muito parecidas entre si, e restritivo - no sentido de o repertório ser limitado, de tarefas e situações repetitivas -, pois a atualização das atividades não era tão rápida, fato este que se refletia no trabalho daqueles professores que utilizavam, com regularidade, o laboratório de informática.

A P1 utilizou a conta de e-mail de cada aluno para que pudessem trocar impressões e comentários sobre um livro paradidático lido; nesse caso, utilizou o provedor de cada aluno para atingir seus objetivos, acesso esse totalmente liberado no CF. O segundo projeto realizado por P1 dizia respeito ao gênero digital weblog: seu formato organizacional, linguagem utilizada nos posts, efeito que as imagens causavam no interlocutor nesse gênero - blog. Nesse projeto, P1 solicitava aos alunos da turma que possuíam blog - pessoal - que disponibilizassem seus endereços eletrônicos para que os demais alunos pudessem acessá-lo e, após a leitura do blog, pudessem responder uma atividade sobre esse gênero discursivo digital. O terceiro projeto realizado foi a produção de $\mathrm{HQ}$, a partir de um software livre: o Hagáquê. Este era um programa gratuito para criação de historinhas, que permitia a impressão e a publicação na internet; sintetizando, era um editor de histórias em quadrinhos com fins pedagógicos. 
A P3 utilizou para a realização dos seus dois projetos (Copa do Mundo de Futebol e Gravidez na Adolescência), o construtor gratuito de sites Wix, o qual estava disponível na rede e foi pesquisado, baixado e disponibilizado aos alunos pelo webmaster. O Wix era um site que oferecia um serviço gratuito de criação on-line de websites: permitia criar, em pouco tempo, sites com aparência profissional, cheios de cores, sons e animações. O aluno aprendia a fazer um site sem a necessidade de se preocupar com código algum de programação ou web. Ao final de cada atividade proposta por P3, o webmaster guardava e editava as produções dos alunos no próprio Wix. Quando o projeto chegava ao fim, era publicado na Web 2.0; o site da turma, então, era compartilhado com o mundo.

\section{DINÂMICA DA AULA DE LP NO LABORATÓRIO DE INFORMÁtICA DA ESCOLA}

Uma das questões que nos chamou a atenção, nessa categoria, diz respeito à maneira como as professoras iniciavam e finalizavam suas aulas no laboratório de informática da escola. P1 sempre iniciava suas aulas no laboratório de informática fazendo uma síntese do conteúdo trabalhado em sala de aula até chegar ao conteúdo a ser trabalhado no laboratório, mediado pelas novas TDICs. Observamos que ela tinha um planejamento de uso das TDICs integrado ao plano de LP da série, ao conteúdo a ser ministrado naquele ano, porque as atividades de língua materna a serem desenvolvidas com as TDICs eram um continuum das atividades realizadas em sala de aula. Apesar de ter dito na entrevista que não tinha formação na área, ela desenvolvia muito bem suas aulas no laboratório de informática. No que diz respeito, especificamente, ao uso das ferramentas, demonstrava ter conhecimento e domínio dos softwares utilizados nas atividades propostas de LP.

P2 iniciava suas aulas dando o "comando de trabalho" da atividade a ser realizada; algumas vezes, ela fazia referência ao conteúdo de LP que os alunos estavam estudando, e quando era questionada por alguns deles sobre o conteúdo da disciplina de LP a ser produzido naquele momento, ela recordava algumas características do tipo ou gênero textual que eles deveriam produzir no momento. A revisão dos conteúdos disciplinares que se pretendia trabalhar no espaço do laboratório de informática a partir das TDICs era um fator diferencial na prática de P1 e P2. Para alguns alunos poderia ser prioritária, pois a dúvida desses alunos não estava focada na ferramenta tecnológica, mas, sim, no conteúdo de LP a ser produzido. Isso pode ter acontecido, inferimos, porque o conteúdo não estava sendo ministrado em uma sequência com relação à atividade proposta com as novas TDICs ou os alunos poderiam ter trabalhado com o conteúdo há algum tempo.

Observamos que a P3 sempre iniciava suas aulas pela "revisão das etapas vivenciadas" pelos alunos em sala de aula, na sequência didática estabelecida para o 
projeto. Em uma das aulas observadas, ela iniciou a orientação pelo tema proposto para o projeto "Gravidez na Adolescência"; na sequência, recordou a análise, interpretação do texto-base do projeto, realizada por eles em sala de aula; reforçou o tipo e o gênero desse texto-base, de qual suporte fora retirado, os recursos argumentativos de que lançou mão o autor do texto, os quais tinham sido listados previamente pelos alunos. E, a partir desse ponto, propôs que eles continuassem o trabalho, agora, com o apoio das novas TDICs.

Acreditamos que o tipo de orientação que os professores de LP fornecem aos alunos no início da atividade solicitada com o uso das TDICs deveria retomar, sintetizar, o conteúdo já ministrado em sala de aula, a exemplo do que fazia P1.

\section{USOS E EFEITOS DAS TDICS: ATIVIDADES DE LP SOLICITADAS AOS ALUNOS NO LABORATÓRIO DE INFORMÁTICA DA ESCOLA}

Um dos questionamentos que nos fazíamos era sobre o motivo que as professoras teriam para realizar projetos utilizando-se das TDICs para ensinoaprendizagem de LP. Os projetos realizados não foram sugeridos pelos livros didáticos de LP (doravante LDPs), que elas adotavam à época da pesquisa. Constatamos, porém, que P2 e P3 utilizavam-se das atividades de outros LDPs como fonte de pesquisa para seus projetos. Assim, concluímos que as professoras observadas não realizavam projetos de uso das TDICs no ensino de LP, porque o livro didático adotado sugeria. Todas elas utilizavam as novas TDICs mais por desejo de desenvolver uma prática voltada para as necessidades de uso social dos alunos, uma prática que fosse ao encontro das expectativas dos alunos, que, como nativos digitais, já se utilizavam de blogs, e-mail, possuíam Facebook, "twitavam".

No caso de $\mathrm{P} 2$ registramos, também, que os serviços do Portal eram pagos, o que fazia com que os professores do CP tivessem certa "obrigação" de usar a tecnologia disponibilizada nas suas aulas, tendo em vista que, na rede privada de ensino, a tecnologia digital aparece como fator gerador de marketing positivo (FREITAS, 2009, p. 70), fator diferencial de qualidade oferecido pelos colégios e marca de atualização.

Com relação às atividades de LP solicitadas pelas professoras, estabelecemos dois eixos que merecem ser comentados: leitura e produção de textos.

a) Leitura: nesse eixo questionávamos se havia ensino de estratégias de leitura para os textos encontrados nos ambientes digitais, que leitura era essa no meio digital (o que liam os alunos) e qual a qualidade dessa leitura. Esclarecemos que todas as atividades realizadas pelas professoras envolviam a leitura global de orientações de uso das ferramentas ou de execução das atividades: leitura dos quadrinhos produzidos, leitura dos parágrafos de textos, leitura em busca de informações (pesquisa na rede).

Retomando as ideias propostas por Gomes (2010, p. 104), observamos que P1, no projeto de leitura de $\operatorname{blogs}$, tinha como propósito a leitura em busca de informações 
específicas sobre um determinado gênero digital. Os alunos teriam que ler blogs pessoais de colegas da turma, no intuito de responder a uma "ficha" sobre o gênero digital weblog: linguagem utilizada no blog, o efeito que as imagens causavam no blog. Observamos que os alunos, ao acessarem os blogs com esse objetivo pré-estabelecido, não se furtavam de interagir, deixando comentários para os colegas sobre os posts lidos.

Salientamos que não havia, no momento da aula no laboratório, ensino de estratégias de leitura dos textos acessados, talvez, por essas estratégias terem sido discutidas em sala de aula ou por não fazerem parte, diretamente, do objetivo estabelecido para as atividades. Constatamos o domínio que os alunos tinham de acesso ao material solicitado, a satisfação advinda da leitura casual dos posts (GOMES, 2010, p. 104), "lendo linearmente" as tirinhas encontradas e seguindo outros links disponibilizados pelos blogueiros. A atividade de leitura do blog solicitada por P1 propiciou outros efeitos na aprendizagem de língua materna: interação e colaboração on-line entre alunos, uso da linguagem digital, acesso a outros weblogs, a partir dos hiperlinks disponibilizados e clicados pelos alunos na página do blog visitado.

A atividade de leitura observada na aula da P2 não ocorreu no laboratório de informática da escola, mas, sim, na sala de aula. Dessa forma, P2 permaneceu em sala de aula com metade da turma e desenvolveu o trabalho sobre bullying na internet. Na proposta de retextualização da P3 - Projeto Gravidez na Adolescência - observamos a leitura dirigida, especificamente, aos objetivos do projeto.

A nossa impressão, a partir das aulas observadas de P1 e P2, é a de que, nesse eixo específico - leitura - apesar de os alunos realizarem a atividade no espaço digital, essa leitura na rede não nos pareceu fonte de ensino e geradora de aprendizagem de LP. Fato contrário ao que aconteceu nas aulas de P3, que constituiu exceção, pois a docente envolvia de tal forma seus alunos, em um processo de leitura dirigida, que propiciava, ao mesmo tempo, aprendizagem de estratégias de leitura.

b) Produção de Textos: nesse eixo, observamos o quanto as práticas com as novas TDICs cumpriam ou não condições de produção de texto, na perspectiva sociointeracionista; quais eram os gêneros digitais solicitados aos alunos e se as condições de produção do gênero eram explicitadas no espaço do laboratório de informática.

O gênero discursivo mais solicitado pelas professoras de LP foi a HQ digital (P1 e P2). Talvez pela facilidade de uso da ferramenta utilizada - no caso da P1, disponibilizada em rede, por ser um software livre; no caso de P2, disponibilizada pelo Portal. Também achamos que a motivação, atração inerente ao gênero HQ digital e as similaridades com o gênero textual HQ teriam sido fatores de escolha pelas professoras desse $e$-gênero.

Realizamos uma breve comparação entre as HQ digitais produzidas pelos alunos da P1 e pelos da P2. Elencamos alguns fatores positivos e negativos da atividade de produção da HQ digital realizada por cada professora. P1, pela escolha do software livre como ferramenta de aprendizagem, propiciou que seus alunos experimentassem, além da escrita da história em quadrinhos em si, a pesquisa na rede de personagens, cenários e, até, balões da comunicação, deixando os estudantes livres para consultas, seguindo 
um ritmo próprio de aprendizagem, orientando-os quando necessário e, quando presente no laboratório de informática, consequentemente, propiciando liberdade de enredo a eles. Observamos a aprendizagem colaborativa propiciada pela atividade solicitada por $\mathrm{P} 1$, na qual os alunos realizaram trocas com seus pares e contribuíram com suas ideias e concepções prévias. Constatamos que as HQ digitais produzidas pelos alunos da P1 eram únicas, heterogêneas entre si.

Na aula observada da P2, pela necessidade de uso das ferramentas, softwares disponibilizados pelo Portal, a produção das HQ foi limitada pelo ambiente de aprendizagem em questão, restringindo o potencial criativo dos alunos $\mathrm{e}$ homogeneizando as HQ produzidas por eles.

A P3, para concretizar seu planejamento, que incluía como objeto de estudo a criação de um site, a partir de uma homepage, contou com a orientação do webmaster, principalmente no que diz respeito às condições de circulação da produção dos alunos. A professora revelou-nos suas impressões sobre o projeto de LP realizado, atrelado às novas TDICs:

P3: Optar por refletir sobre as práticas sociais de escrita sob a ótica da produção hipertextual foi um desafio incomum, diante das adversidades que nós, educadores, nos deparamos, ao buscar tornar efetiva nossa prática docente. Numa atividade de retextualização digital é fundamental a funcionalidade de publicação na $w e b$, principal característica do hipertexto on-line. Mergulhar no ciberespaço é unir esforços e construir rotas possíveis em processos comunicativos, por meio dos quais possamos interagir com o mundo. Com as modificações que realizamos em um texto-base até transformá-lo num hipertexto, constatamos que as desorientações atribuídas ao hipertexto derivam da falta de organização do fluxo de informações. Estas são, quase sempre, amontoadas na tela e não há a preocupação em expor uma orientação argumentativa que leve em consideração as variantes relacionadas ao ambiente de circulação.

O que P3 explicitou, acima, vai ao encontro do que propõem as competências de produção no meio digital, na web: "Aprender a escrever em forma de hipertexto significa [...] ter uma atitude crítica sobre a criação de links e de sua tipologização, muito afastada da navegação ingênua que ocorre na internet" (BURBULES; CALLISTER, 2000, p. 54-55). Dessa forma, a coerência e a coesão no link e entre os links são fatores relevantes na produção de hipertextos hipermodais, para que não se incorra no erro de, simplesmente, "criar desorientações" em rede e postá-las na web.

\section{CONSIDERAÇõES FINAIS}

$\mathrm{O}$ processo de pesquisa percorrido foi de fundamental importância para o entendimento das práticas e táticas utilizadas por professoras para inclusão das TDICs no ensino-aprendizagem de LP. Concluímos que a professora da rede estadual de ensino - P3 - foi a que mais se destacou no que diz respeito ao ensino-aprendizagem de LP a partir do uso das novas TDICs. Isso porque seu planejamento, aliado às tecnologias 
digitais, realizado em conjunto com um aluno-webmaster, que exercia a função do programador - proposta pela TI, a despeito de todas as dificuldades encontradas ao longo das observações -, propiciava a realização de atividades de língua cuidadosamente pesquisadas e preparadas, que geravam conflitos cognitivos, os quais propiciaram aprendizagem.

Dessa forma, entendemos as novas TDICs como meio de aprendizagem, meio carregado de conteúdo, que desloca o foco que vem sendo dado ao seu uso - como recurso didático apenas - e favorece o letramento digital de todos: crianças, jovens alunos, professores, funcionários, ensejando sua inclusão no projeto político pedagógico da escola.

Estamos cientes de que os professores são parte integrante das mudanças como responsáveis pela transposição dos saberes; as escolhas que deverão ser realizadas pelas instituições escolares, como responsáveis pela preparação dos seus alunos para a vida em sociedade passam, necessariamente, por uma revisão de conduta, tendo em vista a velocidade de produção e mudanças no conhecimento, visando uma pedagogia dos multiletramentos.

\section{REFERÊNCIAS}

BALACHEFF, Nicolas. Benefits and limits of social interaction: the case of teaching mathematical proof. In: BISHOP, Alan; MELLIN-OLSEN, Stieg; DORMOLEN, Van. (Ed.). Mathematical knowledge: its growth through teaching. Dordrecht: Kluwer Academic Publisher, 1991. p. 175-192.

BALACHEFF, Nicolas. La transposition informatique. Note sur um nouveau problème pour La didactique. In: ARTIGUE, Michèle et al. (Ed.). Vingt ans de didactique des mathématiques en France. Recherches em Didactique dés

Mathématiques, v. especial. La Pensée Sauvage Editions, 1994. p. 364-370.

BARDIN, Laurence. Análise de Conteúdo. Lisboa: Edições 70, 1979.

BONILLA, Maria Helena. Escola Aprendente: comunidade em fluxo. In: FREITAS, Maria Teresa de Assunção (Org.). Cibercultura e Formação de Professores. Belo Horizonte: Autêntica, 2009

BURBULES, Nicholas; CALLISTER, Thomas. A. Jr. Hypertext: knowledge at the crossroads. In: BURBULES, Nicholas; CALLISTER, Thomas. Watch it: the risks and promises of information technologies for education. Oxford: Westview Press, 2000.

CHEVALLARD, Yves. La Transpositión didáctica: del saber sábio ao saber enseñado. Buenos Aires. Aique Grupo Editor, 1991. 
CONRAUX, Lionel. Une étude de la transposition informatique à l'oeuvre dans l'interface des logiciels éducatifs. Les cahiers Théodile, v.1, n. 1, p. 141-157, Nov. 2000. Disponível em : <http:// theodile.recherche.univ-lille3.fr/spip.php ?rubrique2>. Acesso em: 13 jul. 2010.

FREITAS, Maria Teresa de Assunção (Org.). Cibercultura e formação de professores. Belo Horizonte: Autêntica, 2009.

GOMES, Luiz Fernando. Hipertextos multimodais: leitura e escrita na era digital. Jundiaí: Paco Editorial, 2010.

KALANTZIS, Mary; COPE, Bill. Changing the role of schools. In: COPE, Bill; KALANTZIS, Mary (Org.). Multiliteracies: literacy learning and the design of social futures. New York: Routledge, 2000.

LEMKE, Jay. Metamedia literacy: transforming meanings and media. In: REINKING, David et al. (Org.). Handbook of literacy and technology: transformations in a posttypographic world. Hillsdale: Erlbaum, 1998, p. 283-301.

MARTINAND, Jean Louis. Connaître et transformer la matière: des objectives pour I'initiation aux sciences et techniques. Berne: Editions Peter Lang, 1986.

ROJO, Roxane. Pedagogia dos multiletramentos: diversidade cultural e de linguagens na escola. In: ROJO, Roxane; MOURA, Eduardo (Org.). Multiletramentos na escola. São Paulo: Parábola Editorial, 2012.

Como citar este texto:

CAIADO, Roberta Varginha Ramos; MORAIS, Artur Gomes. Práticas de ensino de língua portuguesa com as TDIC. ETD - Educação Temática Digital, Campinas, SP, v. 15, n. 3, p.578-594, set./dez. 2013. ISSN 1676-2592. Disponivel em: <http://www.fae.unicamp.br/revista/index.php/etd/article/view/5568>. Acesso em: 21 dez. 2013. 